\title{
Prevalence of abnormal glucose tolerance in Indian women with polycystic ovarian syndrome
}

\section{Chandana C.*, Aparna Nair, Sampath Kumar G.}

Department of Obstetrics and Gynecology, Vydehi Institute of Medical Sciences and Research Centre, Bengaluru, Karnataka, India

Received: 13 September 2016

Accepted: 20 October 2016

\author{
*Correspondence: \\ Dr. Chandana C, \\ E-mail: chandanachandregowda@gmail.com
}

Copyright: () the author(s), publisher and licensee Medip Academy. This is an open-access article distributed under the terms of the Creative Commons Attribution Non-Commercial License, which permits unrestricted non-commercial use, distribution, and reproduction in any medium, provided the original work is properly cited.

\begin{abstract}
Background: Polycystic ovarian syndrome is a common endocrine condition affecting reproductive age women, associated with impaired glucose intolerance (IGT) and type 2 diabetes mellitus (DM). The aim of this study was to analyze the prevalence of IGT and type $2 \mathrm{DM}$ in Indian polycystic ovarian syndrome patients as compared to control population.

Methods: This prospective cross sectional study included 130 PCOS women and 76 control women attending OBG department Vydehi medical college and research centre. From all included subject's clinical history, family history and anthropometric measurements were obtained. All women had a standard oral glucose tolerance test (OGTT) with measurement of fasting glucose and 2-hour glucose levels. Normal glucose tolerance (NGT), IGT, and type 2 diabetes were defined using glucose levels during the OGTT, according to the criteria proposed by the World Health Organization (WHO)

Results: Among 130 PCOS women, glucose tolerance was normal in 101 (77.69\%) women, 25 (19.2\%) had IGT and $4(3.07 \%)$ had type $2 \mathrm{DM}$; compared to 76 healthy controls, $70(92.1 \%)$ had normal glucose tolerance and $6(7.9 \%)$ had IGT. None of the controls had type 2 DM. This finding was statistically significant with $\mathrm{P}$ value 0.02 .

Conclusions: The prevalence of IGT and type 2 DM in women with PCOS is significantly more in comparison with healthy controls. Therefore, women with PCOS should periodically have an OGTT for diabetes screening.
\end{abstract}

Keywords: Diabetes mellitus (DM), Impaired glucose intolerance (IGT), Oral glucose tolerance test (OGTT), Polycystic ovarian syndrome (PCOS)

\section{INTRODUCTION}

Polycystic ovarian syndrome (PCOS) is a common endocrine condition estimated to affect $4-18 \%$ of women of reproductive age. ${ }^{1,2}$ PCOS has also been associated with long-term metabolic effects, including the development of insulin resistance, diabetes mellitus, hyperlipidemia, non-alcoholic steatohepatitis (NASH) and an adverse risk profile for cardiovascular disease. ${ }^{3}$ More than $50 \%$ of women with PCOS are insulin resistant, and it is estimated that they have a 5 to 8 fold increased risk of type 2 diabetes mellitus (type 2 DM), when compared with age and weight-matched controls., ${ }^{4,5}$ However, IGT can be underdiagnosed, even in populations at high risk, because the diagnosis of IGT needs an oral glucose tolerance test (OGTT). ${ }^{6,7}$ As PCOS is common condition affecting women of reproductive age, this represents a significant population burden of disease for the future. The primary aim of this prospective study was to determine the prevalence of IGT and type $2 \mathrm{DM}$ in PCOS women as compared to control women.

\section{METHODS}

Our prospective study included 130 PCOS women and 76 Control women, aged 18-40 years. 130 women with PCOS, all in the reproductive age (range16-40 years), 
who consecutively attended the OBG department VIMS and RC from January 2014 to December 2015. The diagnosis of PCOS was made by the presence of chronic anovulation, hyperandrogenemia, and polycystic ovarian morphology at ultrasound examination. Control women were in good health had menses every $28 \pm 2$ days and were not hirsute. None of the control subjects had family history of diabetes mellitus. None of the subjects included in the study had thyroid, cardiovascular, renal, or liver dysfunctions based on clinical examination and routine laboratory findings. They had not taken any medication known to affect glucose metabolism during the 3 months prior to the study or were dieting.

The study protocol was approved by the ethics committee VIMS and RC, and all subjects enrolled in the study signed an informed consent. The clinical and family history and information on dietary habits and habitual physical activity were obtained from each subject. Height, weight, waist-to-hip ratio (WHR) and BMI $\left(\mathrm{kg} / \mathrm{m}^{2}\right)$ were measured according to standardized procedures.

An oral glucose tolerance test (OGTT) 75 grams was performed, with venous blood samples taken at fasting and 2 hours after the glucose load for glucose measurement. Normal glucose tolerance (NGT), IGT, and type 2 diabetes were defined using glucose levels during the OGTT, according to the criteria proposed by the World Health Organization (WHO). Criteria based on fasting glucose $<110 \mathrm{mg} / \mathrm{dl}$ and 2 hour plasma glucose $<140 \mathrm{mg} / \mathrm{dl}$ were normal. Impaired Glucose tolerance (IGT) diagnosed based on Fasting plasma glucose $>110$ $\mathrm{mg} / \mathrm{ml}$ and $<126 \mathrm{mg} / \mathrm{dl}$ and 2 hour plasma glucose $>140$ $\mathrm{mg} / \mathrm{dl}$ and $<200 \mathrm{mg} / \mathrm{dl}$. Diabetes based on Fasting plasma glucose $>126 \mathrm{mg} / \mathrm{dl}$ and 2 hour plasma glucose> $200 \mathrm{mg} / \mathrm{dl}$.

\section{Statistical analysis}

All data are expressed as mean $\pm \mathrm{SD}$, frequencies as percentage. Continuous data were compared between the two groups using independent sample t-test. The differences between groups were assessed using unpaired $\mathrm{t}$ - test for parametric data and Mann-Whitney U test for nonparametric data. Correlations between variables were evaluated with the use of Spearman's correlation coefficient. To analyze the effects of PCOS on glucose parameters, analysis of covariance (ANCOVA) was applied with BMI as covariate. For all analyses, a twotailed $\mathrm{P}$ value of $<0.05$ was considered to indicate statistical significance.

\section{RESULTS}

Our study included 130 women diagnosed with PCOS and 76 healthy women as control. The comparison of clinical and biochemical parameters between women with PCOS and healthy subjects is given in Table 1 . The mean age of women with PCOS was $27.5 \pm 4.7$ (years) that are comparable with the healthy subjects $26.2 \pm 4.9$ (years). The mean BMI was higher in PCOS women (26.6 \pm 3.6$)$ as compared to healthy control $(24.6 \pm 3.6)$, which was statistically significant $(\mathrm{p}=0.002)$. Similarly waist to hip ratio was statistically high in PCOS women compared to healthy controls ( $\mathrm{P}$ value 0.02) Hence in our study women with PCOS were more overweight and obese than the control subjects. The fasting glucose level was significantly high in PCOS women $(101.3 \pm 6.1)$ compared to healthy controls $(88 \pm 5.6)$ with $\mathrm{P}$ value 0.0001 . The OGTT 2 hour glucose level was significantly high in PCOS group (181 \pm 11.7$)$ compared to control group $(135.1 \pm 12.1)$ with $P$ value 0.0001 .

Table 1: Clinical and biochemical parameters in women with PCOS and healthy controls.

\begin{tabular}{|llll|}
\hline Variable & $\begin{array}{l}\text { PCOS } \\
(\mathrm{n}=130)\end{array}$ & $\begin{array}{l}\text { Control } \\
(\mathrm{n}=76)\end{array}$ & $\begin{array}{l}\mathrm{P} \text { - } \\
\text { value }\end{array}$ \\
\hline Age & $27.5 \pm 4.7$ & $26.2 \pm 4.9$ & 0.08 \\
\hline BMI $\left(\mathrm{kg} / \mathrm{m}^{2}\right)$ & $26.6 \pm 3.6$ & $24.6 \pm 3.6$ & 0.002 \\
\hline Waist to hip ratio & $0.82 \pm 0.2$ & $0.76 \pm 0.1$ & 0.02 \\
\hline $\begin{array}{l}\text { Fasting glucose } \\
(\mathrm{mg} / \mathrm{dl})\end{array}$ & $101.3 \pm 6.1$ & $88.0 \pm 5.6$ & 0.0001 \\
\hline $\begin{array}{l}\text { OGTT 2-hr } \\
\text { glucose }(\mathrm{mg} / \mathrm{dl})\end{array}$ & $181 \pm 11.7$ & $135.1 \pm 12.1$ & 0.0001 \\
\hline
\end{tabular}

Data are shown as mean \pm SD. $\mathrm{P}$ value $<0.05$ was considered statistically significant.

PCOS, Polycystic ovarian syndrome; OGTT, oral glucose tolerance test; BMI, body mass index

Table 2: Clinical and biochemical parameters according to glucose status in women with PCOS and healthy controls.

\begin{tabular}{|c|c|c|c|c|c|c|}
\hline \multirow[b]{2}{*}{ Variables } & \multicolumn{3}{|l|}{ PCOS } & \multicolumn{3}{|l|}{ Control } \\
\hline & NGT (n=101) & IGT (n=25) & Type 2 DM (n=4) & NGT (n=70) & IGT (n=6) & $\begin{array}{l}\text { Type } 2 \text { DM } \\
(n=0)\end{array}$ \\
\hline Age (years) & $26.3 \pm 5.6$ & $27.1 \pm 5.1$ & $29.2 \pm 3.4$ & $25.9 \pm 4.9$ & $26.6 \pm 3.7$ & 0 \\
\hline BMI $\left(\mathrm{kg} / \mathrm{m}^{2}\right)$ & $23.5 \pm 3.2$ & $27.2 \pm 5.7$ & $29.2 \pm 2.1$ & $23.1 \pm 4.2$ & $26.2 \pm 3.1$ & 0 \\
\hline Waist to hip ratio & $0.81 \pm 0.3$ & $0.82 \pm 0.2$ & $0.84 \pm 0.3$ & $0.76 \pm 0.1$ & $0.77 \pm 0.2$ & 0 \\
\hline Fasting glucose (mg/dl) & $83.5 \pm 4.1$ & $96 \pm 5.3$ & $125.3 \pm 8.8$ & $81.2 \pm 4.7$ & $94.8 \pm 6.6$ & 0 \\
\hline $\begin{array}{l}\text { OGTT 2-h glucose } \\
(\mathrm{mg} / \mathrm{dl})\end{array}$ & $115.7 \pm 6.9$ & $167 \pm 11.3$ & $260.5 \pm 17.1$ & $110.4 \pm 7.3$ & $159.8 \pm 10.7$ & 0 \\
\hline
\end{tabular}

Data are shown as mean \pm SD. NGT, normal glucose tolerance; IGT, impaired glucose tolerance; DM, diabetes mellitus; PCOS, Polycystic ovarian syndrome; OGTT, oral glucose tolerance test 
Clinical and biochemical parameter according to glucose status in women with PCOS and healthy controls is given in Table 2. Among 130 PCOS women, glucose tolerance was normal in 101(77.69\%) women, $25(19.2 \%)$ had IGT and $4(3.07 \%)$ had type $2 \mathrm{DM}$. In comparison to 76 healthy controls, $70(92.1 \%)$ had normal glucose tolerance and $6(7.9 \%)$ had IGT. None of the controls had type 2 DM.

The age and BMI stratified prevalence of glucose intolerance in women with PCOS and a healthy control is given in Table 3 . Of the 130 patients with PCOS, 35
(26.9\%) were overweight (BMI $\geq 25 \mathrm{~kg} / \mathrm{m}^{2}$ ) and 27 $(20.7 \%)$ were obese (BMI $\left.\geq 30 \mathrm{~kg} / \mathrm{m}^{2}\right)$, whereas $16(21 \%)$ of 76 control patients were overweight and $8(10.5 \%)$ were obese. In the PCOS group, 20/130 (15.4\%) women and in control group 20/76 (26.3\%) were older than 30 years. Among 86 women with BMI >25, 30 women (34.8\%) had abnormal glucose tolerance (IGT and type 2 DM). Among 40 women with age $>30$ years, 14 (35\%) had abnormal glucose tolerance (IGT and type $2 \mathrm{DM}$ ). Hence prevalence rate of IGT and type $2 \mathrm{DM}$ were more with increased age and BMI. PCOS women with family history of diabetes were more likely to have IGT and type 2 DM.

Table 3: The age and BMI stratified prevalence of glucose intolerance in women with PCOS and healthy controls.

\begin{tabular}{|c|c|c|c|c|c|c|c|c|}
\hline & \multicolumn{4}{|c|}{$\operatorname{PCOS}(n=130)$} & \multicolumn{4}{|c|}{ Control $(n=76)$} \\
\hline & n & NGT (\%) & IGT (\%) & Type 2 DM (\%) & $\mathbf{n}$ & NGT (\%) & IGT (\%) & Type 2 DM (\%) \\
\hline \multicolumn{9}{|c|}{ BMI $\left(\mathrm{kg} / \mathrm{m}^{2}\right)$} \\
\hline$<25$ & 68 & $58(85.3 \%)$ & $10(14.7 \%)$ & 0 & 52 & $52(100 \%)$ & 0 & 0 \\
\hline $25-30$ & 35 & $27(77.1 \%)$ & $7(20 \%)$ & $1(2.9 \%)$ & 16 & $13(81.25 \%)$ & $3(18.75 \%)$ & 0 \\
\hline$>30$ & 27 & $16(59.2 \%)$ & $8(29.6 \%)$ & $3(11.2 \%)$ & 8 & $5(62.5 \%)$ & $3(37.5 \%)$ & 0 \\
\hline \multicolumn{9}{|c|}{ Age (years) } \\
\hline$<25$ & 75 & $68(90.6 \%)$ & $7(9.4 \%)$ & 0 & 40 & $39(97.5 \%)$ & $1(2.5 \%)$ & 0 \\
\hline $25-30$ & 35 & $30(85.7 \%)$ & $3(8.5 \%)$ & $1(2.8 \%)$ & 16 & $15(93.75 \%)$ & $1(6.25 \%)$ & 0 \\
\hline $31-35$ & 14 & $8(57.15 \%)$ & $5(35.7 \%)$ & $1(7.15 \%)$ & 14 & $13(92.86 \%)$ & $1(7.14 \%)$ & 0 \\
\hline $36-40$ & 6 & $2(33.3 \%)$ & $2(33.3 \%)$ & $2(33.3 \%)$ & 6 & $3(50 \%)$ & $3(50 \%)$ & 0 \\
\hline
\end{tabular}

NGT, normal glucose tolerance; IGT, impaired glucose tolerance; DM, diabetes mellitus; PCOS, Polycystic ovarian syndrome; BMI, body mass index

\section{DISCUSSION}

The diagnosis of PCOS was based on the revised criteria of the European Society of Human Reproduction and Embryology/American Society for Reproductive Medicine in 2003 (The Rotterdam ESHRE/ ASRMSponsored PCOS Consensus Workshop Group, 2004). The diagnosis of PCOS was made by the presence of (i) oligomenorrhoea and/or anovulation (eight or fewer menstrual cycles in a year or menstrual cycles more than 35 days in length) (ii) clinical and/or biochemical signs of hyperandrogenism and (iii) polycystic ovaries (presence of 12 or more follicles in each ovary measuring $2-9 \mathrm{~mm}$ in diameter and/or increased ovarian volume $>10 \mathrm{ml}$ ) and exclusion of other etiologies (e.g. congenital adrenal hyperplasia, androgen-secreting tumors and Cushing's syndrome). PCOS is associated with metabolic effects like increased risk of IGT, type 2 DM, cardiovascular disease and psychological sequelae like impaired quality of life and increased anxiety and depression.,

In our study, performed on Indian population found that the prevalence rate of type $2 \mathrm{DM}, 4(3.07 \%)$ and IGT, 25 $(19.23 \%)$ of 130 PCOS women as compared to type 2 DM $0 \%$ and IGT $6(7.08 \%)$ of 76 healthy controls which is statistically significant with $\mathrm{P}$ value 0.0001 . Our findings were similar to that reported from cohort of Mediterranean women and Turkish women with PCOS. (Gambineri et al and cem celik et al). ${ }^{10,11}$ Ehrmann et al, in his study demonstrated very high prevalence of IGT and type $2 \mathrm{DM}^{12}$ Our study demonstrated that women with Type 2 DM are older (mean age 29.2 $\pm 3.4 y r s$ ) than women with normal or IGT, similar finding have been demonstrated in previous study (Harris et al). ${ }^{6}$ But Ehrmann et al and Legro et al, in their study found no significance in prevalence of IGT and type 2 DM in different age groups. ${ }^{12,13}$ From previous studies, data demonstrated that the prevalence of abnormal glucose intolerance significantly increased with BMI. In this study women with PCOS were obese than the controls, but were comparable with age. The waist hip ratio was more in women with PCOS. Our study demonstrated an association between abnormal glucose tolerance with BMI and waist hip ratio findings similar to other studies (Ehrmann et al and Legro et al). ${ }^{12,13}$ Some evidence suggests that women with PCOS have a greater predisposition to obesity which may aggravate PCOSrelated intrinsic insulin resistance and associated reproductive and metabolic disturbances. ${ }^{12}$

It has been documented that a family history of diabetes worsens insulin secretion and glucose tolerance in PCOS. 
Likewise, we showed that a first degree relative with diabetes was associated with an increased risk of glucose intolerance in PCOS. It was reported previously that most of the women with PCOS and glucose intolerance had normal fasting blood glucose (FBG), and this suggested that the OGTT test was the best screening measure for glucose intolerance and diabetes in women with PCOS). ${ }^{14}$

PCOS is also identified as a significant non-modifiable risk factor associated with DM2 by the International Diabetes Federation (Alberti et al) and women with PCOS are also proposed to have a more rapid conversion from IGT to DM2 (Norman et al). ${ }^{15,16}$

Furthermore, women with PCOS have an elevated prevalence of the metabolic syndrome and individuals with the metabolic syndrome are at increased risk for DM2 and CVD (Lorenzo et al, Cameron et al). ${ }^{17,18}$ Hence PCOS women should be regularly screened for abnormal glucose intolerance to reduce associated long term health complications.

\section{CONCLUSION}

Our study demonstrates an increased prevalence rate of IGT and type $2 \mathrm{DM}$ in women with PCOS in comparison with healthy controls. Women with PCOS are the ideal population to implement diabetes screening with OGTT periodically and can be targeted for preventive interventions with ultimate goal of reducing the enormous impact of type $2 \mathrm{DM}$ on quality of life.

Funding: No funding sources

Conflict of interest: None declared

Ethical approval: The study was approved by the Institutional Ethics Committee

\section{REFERENCES}

1. Diamanti-Kandarakis E, Kouli CR, Bergiele AT, Filandra FA, Tsianateli TC, Spina GG, et al. A survey of the polycystic ovary syndrome in the Greek island of Lesbos: hormonal and metabolic profile. J Clin Endocrinol Metab. 1999;84:4006-11.

2. March WA, Moore VM, Willson KJ, Phillips DI, Norman RJ, Davies MJ. The prevalence of polycystic ovary syndrome in a community sample assessed under contrasting diagnostic criteria. Hum Reprod. 2010; 25:544-51.

3. Asunción M, Calvo RM, San Millán JL, Sancho J, Avila S, Escobar-Morreale HF. A prospective study of the prevalence of the polycystic ovary syndrome in unselected Caucasian women from Spain. J Clin Endocrinol Metab. 2000;85:2434-38.

4. Glintborg D, Henriksen JE, Andersen M, Hagen C, Hangaard J, Rasmussen PE. Prevalence of endocrine diseases and abnormal glucose tolerance tests in 340 Caucasian premenopausal women with hirsutism as the referral diagnosis. Fertil Steril. 2004;82:1570-79.
5. Glintborg D, Andersen M. An update on the pathogenesis, inflammation, and metabolism in hirsutism and polycystic ovary syndrome. Gynecol Endocrinol. 2010;26:281-96.

6. Harris MI, Hadden WC, Knowler WC, Bennett PH. Prevalence of diabetes and impaired glucose tolerance and plasma glucose levels in U.S. population aged 20-74 yr. Diabetes. 1987;36:523-34.

7. King H, Rewers M. WHO Ad Hoc Diabetes, Reporting Group: global estimates form prevalence of diabetes mellitus and impaired glucose tolerance in adults. Diabetes Care. 1993;16:157-77.

8. Azziz R, Carmina E, Dewailly D, DiamantiKandarakis E, Escobar-Morreale HF, Futterweit W, et al. Position statement: criteria for defining polycystic ovary syndrome as a predominantly hyperandrogenic syndrome: an Androgen Excess Society guideline. J Clin Endocrinol Metab. 2006;91:4237-45.

9. Himelein MJ, Thatcher SS. Polycystic ovary syndrome and mental health: a review. Obstet Gynecol Surv. 2006;61:723-32.

10. Gambineri A, Pelusi C, Manicardi E, Vicennati V, Cacciari M, Morselli-Labate AM, et al. Glucose intolerance in a large cohort of mediterranean women with polycystic ovary syndrome: phenotype and associated factors. Diabetes. 2004;53:2353-58.

11. Celik C, Abali R, Bastu E, Tasdemir N, Tasdemir UG, Gul A. Assessment of impaired glucose tolerance with hemoglobin A1c and oral glucose tolerance test in 252 Turkish women with polycystic ovary syndrome; a prospective controlled study. Hum Reprod. 2013;28:1062-68.

12. Ehrmann DA, Barnes RB, Rosenfield RL, Cavaghan MK, Imperial J. Prevalence of impaired glucose tolerance and diabetes in women with polycystic ovary syndrome. Diabetes Care. 1999;22:141-46.

13. Legro RS, Kunselman AR, Dodson WC, Dunaif A. Prevalence and predictors of risk for type 2 diabetes mellitus and impaired glucose tolerance in polycystic ovary syndrome: a prospective, controlled study in 254 affected women. J Clin Endocrinol Metab. 1999;84:165-69.

14. Lee H, Oh JY, Sung YA, Chung H, Cho WY. The prevalence and risk factors for glucose intolerance in young Korean women with polycystic ovary syndrome. Endocrine 2009;36:326-32.

15. Alberti KG, Zimmet $P$, Shaw J. International Diabetes Federation: a consensus on type 2 diabetes prevention. Diabet Med. 2007;24:451-63.

16. Norman RJ, Masters L, Milner CR, Wang JX, Davies MJ. Relative risk of conversion from normoglycaemia to impaired glucose tolerance or non-insulin dependent diabetes mellitus in polycystic ovarian syndrome. Hum Reprod. 2001;16:1995-98.

17. Lorenzo C, Okoloise M, Williams K, Stern MP, Haffner SM. The metabolic syndrome as predictor of type 2 diabetes: the San Antonio heart study. Diabetes Care. 2003;26:3153-59. 
18. Cameron AJ, Magliano DJ, Zimmet PZ, Welborn T, Shaw JE. The metabolic syndrome in Australia: prevalence using four definitions. Diabetes Res Clin Pract. 2007;77:471-78.
Cite this article as: Chandana C, Nair A, Kumar SG. Prevalence of abnormal glucose tolerance in Indian women with polycystic ovarian syndrome. Int J Reprod Contracept Obstet Gynecol 2016;5:4308-12. 